\title{
Time to Recover From Daily Caffeine Intake
}

\author{
Yu-Shiuan Lin ${ }^{1,2,3}$, Janine Weibel ${ }^{1,2}$, Hans-Peter Landolt ${ }^{4,5}$, Francesco Santini ${ }^{6,7}$, \\ Corrado Garbazza ${ }^{1,2}$, Joshua Kistler ${ }^{1,2}$, Sophia Rehm ${ }^{8}$, Katharina Rentsch ${ }^{8}$, \\ Stefan Borgwardt ${ }^{3}$, Christian Cajochen ${ }^{1,2 *}$ and Carolin F. Reichert ${ }^{1,2}$ \\ ${ }^{1}$ Centre for Chronobiology, University Psychiatric Clinics Basel, Basel, Switzerland, ${ }^{2}$ Transfaculty Research Platform \\ Molecular and Cognitive Neurosciences, University of Basel, Basel, Switzerland, ${ }^{3}$ Neuropsychiatry and Brain Imaging, \\ University Psychiatric Clinics Basel, Basel, Switzerland, ${ }^{4}$ Institute of Pharmacology and Toxicology, University of Zurich, \\ Zurich, Switzerland, ${ }^{5}$ Sleep and Health Zurich, University Center of Competence, University of Zurich, Zurich, Switzerland, \\ ${ }^{6}$ Division of Radiological Physics, Department of Radiology, University Hospital Basel, Basel, Switzerland, ${ }^{7}$ Department of \\ Biomedical Engineering, University of Basel, Basel, Switzerland, ${ }^{\circ}$ Laboratory Medicine, University Hospital Basel, Basel, \\ Switzerland
}

Caffeine elicits widespread effects in the central nervous system and is the most frequently consumed psychostimulant worldwide. First evidence indicates that, during daily intake, the elimination of caffeine may slow down, and the primary metabolite, paraxanthine, may accumulate. The neural impact of such adaptions is virtually unexplored. In this report, we leveraged the data of a laboratory study with $N=20$ participants and three within-subject conditions: caffeine (150 mg caffeine $\times 3 /$ day $\times 10$ days), placebo (150 mg mannitol $\times 3 /$ day $\times 10$ days), and acute caffeine deprivation (caffeine $\times 9$ days, afterward placebo $\times 1$ day). On day 10, we determined the course of salivary caffeine and paraxanthine using liquid chromatography-mass spectrometry coupled with tandem mass spectrometry. We assessed gray matter (GM) intensity and cerebral blood flow (CBF) after acute caffeine deprivation as compared to changes in the caffeine condition from our previous report. The results indicated that levels of paraxanthine and caffeine remained high and were carried overnight during daily intake, and that the levels of paraxanthine remained elevated after $24 \mathrm{~h}$ of caffeine deprivation compared to placebo. After $36 \mathrm{~h}$ of caffeine deprivation, the previously reported caffeineinduced GM reduction was partially mitigated, while CBF was elevated compared to placebo. Our findings unveil that conventional daily caffeine intake does not provide sufficient time to clear up psychoactive compounds and restore cerebral responses, even after $36 \mathrm{~h}$ of abstinence. They also suggest investigating the consequences of a paraxanthine accumulation during daily caffeine intake.

Keywords: paraxanthine, withdrawal, metabolism, brain, caffeine

\section{INTRODUCTION}

Caffeine is the most frequently consumed psychostimulant worldwide. After an acute p.o. administration, $99 \%$ of the caffeine is rapidly absorbed within $\sim 45 \mathrm{~min}$ (1), which brings the peak plasma concentration of caffeine at $1-2 \mathrm{~h}$ after the intake. The average half-life of caffeine after an acute consumption is $2.5-5 \mathrm{~h}$ (2), while it can be modulated by the ingested dosages, smoking, genetic variance, health status, oral contraceptives and pregnancy, and various other factors (3-6). 
Approximately $84 \%$ of caffeine is transformed into paraxanthine through the process of 3-methyl demethylation by the hepatic cytochrome P450 1A2 enzyme (CYP1A2) (2, 5). Following the peak concentration after a single administration of 5-8 $\mathrm{mg} / \mathrm{kg}$ caffeine, plasma concentrations of caffeine decline rapidly and are surpassed by the paraxanthine levels at around 8$10 \mathrm{~h}$ after the intake (7). Paraxanthine has as high potency at antagonizing adenosine receptors as caffeine (8) and exerts several similar effects as caffeine, such as wake-promotion (9), psychostimulation (10), elevating blood pressure, and release of epinephrine (11). Yet, kinetics and concentrations of paraxanthine have rarely been considered when studying the physiological and cognitive outcomes of caffeine intake in humans.

Despite the common pattern of regular intake, studies on the kinetics of caffeine and paraxanthine in humans after daily caffeine intake are surprisingly scarce. In rodents, applying caffeine for 10 days in a $3 \mathrm{~h}$ interval leads to a smaller elimination rate constant $\left(\mathrm{K}_{\mathrm{el}}\right)$ of plasma caffeine concentration after 10 days of caffeine intake compared to acute administration (12). Furthermore, compared to a linear dose-response in a foodlimited state, daily caffeine intake in an ad-libitum dietary state leads to dose-disproportional responses (i.e., the higher the dose the larger increase) in peak levels of caffeine and paraxanthine and the 24-h area under the curve $\left(\mathrm{AUC}_{0-24}\right)(12)$. In humans, only one study compared the metabolism of caffeine in nine adults among baseline $(0 \mathrm{mg} / \mathrm{kg})$, low-dose $(0.7 \mathrm{mg} / \mathrm{kg})$, and high-dose $(2 \mathrm{mg} / \mathrm{kg})$ treatments applied every $2 \mathrm{~h}, 6$ times a day for 5 days (4). The authors reported a dose-dependent deceleration of metabolism of intravenous isotope-labeled (2-'3C, 1,3-'5N2) caffeine after 3 days of treatment (i.e., the higher the dose, the slower the metabolism), and a dose-disproportional elevation in the $\mathrm{AUC}_{0-24}$ of paraxanthine. This study, however, included a rather small sample size with an unusually high dosage, given that the volunteer with the highest weight of $99 \mathrm{~kg}$ could receive up to $1,188 \mathrm{mg} /$ day in the high-dose condition. It remains unclear whether the metabolism during a conventional pattern of daily caffeine intake over a longer time will adapt similarly as in this study. We consider a treatment with a unified dose in the morning, noon, and afternoon hours as more generalizable (13-15).

Although the findings from both rodents and humans summarized in the last paragraph $(4,12)$ consistently suggest an adapted metabolism of caffeine and paraxanthine over the course of daily caffeine intake, no physiological outcomes were available in these studies. An increase of psychoactive compounds may also multiply the impacts in brains, as ex vivo evidence indicates that elevating caffeine concentrations can lead to an increase in the brain-to-plasma ratio of caffeine (16). Previously, we observed a decreased gray matter (GM) in the medial temporal lobe and reduced cerebral blood flow (CBF) during daily caffeine intake, in which the larger reductions of both properties were associated with a higher accumulation of caffeine + paraxanthine. We postulated that these cerebral responses may be due to an incomplete elimination and an accumulation of the psychoactive compounds. It is still unclear, however, how fast these brain responses can be restored during abstinence when caffeine and paraxanthine can be completely eliminated.

In addition to the daily pattern of intake, genetic variations also determine the individual metabolic process and in turn modulate the development of habitual patterns of caffeine intake $(5,17,18)$. In particular, the variants in CYP1A2, AHR, and CYP2A6, which are associated with lower habitual intake (19, 20), are also associated with slower metabolism of caffeine (CYP1A2 and AHR) and paraxanthine [CYP2A6; (19)]. Thus, the adaptions in the metabolism of caffeine and paraxanthine during daily caffeine intake and its physiological effects can be also modulated by the genetic traits reflected by the levels of habitual intake.

For the present report, we assumed that daily moderatedose caffeine intake can lead to an accumulation of caffeine and paraxanthine concentrations. We leveraged salivary samples of a previous study with three within-subject conditions (21): caffeine (150 mg caffeine $\times 3 /$ day $\times 10$ days), placebo $(150 \mathrm{mg}$ mannitol $\times 3$ day $\times 10$ days), and acute caffeine deprivation (caffeine $\times 9$ days + placebo $\times 1$ day). We report a 43 -h profile of caffeine and paraxanthine levels, the kinetics of each compound, and their association with habitual caffeine intake. Moreover, we examined the brain recovery after $36 \mathrm{~h}$ of caffeine deprivation when the levels of caffeine were expected to be cleared. The protocol simulated a conventional pattern of a double espresso at breakfast, lunch, and afternoon-teatime (in 3.25- and 4-h intervals, respectively).

\section{METHODS}

\section{Study Protocol, Participants, and Environmental Control}

In a double-blind, randomized, placebo-controlled study, we included 20 clinically healthy male non-smokers, who were between 18 and 35 years of age with a body mass index between 18 and $26 \mathrm{~kg} / \mathrm{m}^{2}$ and a habitual caffeine intake between 300 and $600 \mathrm{mg} /$ day. The amount of habitual caffeine intake was assessed by a self-report questionnaire adapted from Bühler, Lachenmeier (22), and Snel and Lorist (23).

Each volunteer completed three conditions [orders of condition see (24)]: A placebo condition (150 mg mannitol $\times 3$ / day $\times 10$ days), a daily caffeine condition (150 mg caffeine $\times$ $3 /$ day $\times 10$ days), and an acute caffeine deprivation (caffeine from the first administration up to day 9, then switch to placebo until the end of day 10). Note that a 9-day placebo intake can be considered to be sufficient for a washout of the remaining effects of the participants' prior caffeine intake, at least regarding possible withdrawal symptoms (25). Between each of the conditions, there was at least 1 week of recovery in which caffeine intake was not standardized, as this regular intake pattern was considered to be the status quo. Among the 20 participants (habitual caffeine level mean \pm SD: $474.1 \pm$ $107.5 \mathrm{mg}$ ), 10 participants habitually consumed more and 10 less than the daily dose at the start of the ambulatory part. An additional period of prior abstinence may have introduced more 
variance due to individual differences in the course and responses to caffeine withdrawal.

The outcomes were assessed on day 10 for each condition. Figure 1 presents the study protocol, including the timing of the treatments, the outcome measurements, and the corresponding hours of caffeine deprivation in each condition. We scheduled the MRI scans in all three conditions for all participants at $12 \mathrm{~h}$ after waking up, to control for the confounding effects of different durations of wakefulness (26) and different levels of sleepiness (27) on cerebral variables.

Through the entire 10 days, participants complied with a regular sleep-wake cycle $(8 \mathrm{~h} \pm 30 \mathrm{~min}$ night-time sleep, no naps allowed) according to their habitual bedtime, which was monitored and recorded by actimetry (Actiwatch, Cambridge Neurotechnology, Cambridge, United Kingdom) and sleep diaries. Participants abstained from any other caffeine-containing diets, including coffee, tea, energy drink, soda, and chocolate, and the compliance was monitored by measuring caffeine levels in the evenings. The data of one participant's caffeine condition was excluded due to incompliance with the treatment. The laboratory environment from day 9 evening to day 10 was strictly controlled: dim light, half-supine posture $\left(\sim 45^{\circ}\right)$, and regular dietary and lavatory times. Participants were allowed to sleep for $8 \mathrm{~h}$ in the night between day 9 and day 10. A digital device without time clues and access to the Internet was permitted. Social interaction was restricted to the group of experimenters.

\section{Data Acquisition and Analyses Caffeine and Paraxanthine}

In each condition, we analyzed caffeine and paraxanthine levels in 11 saliva samples, collected in 105-120 min intervals. For the quantification of caffeine, paraxanthine, theobromine, and theophylline, the collected saliva samples were analyzed using a high-performance liquid chromatography system (UltiMate 3000), coupled to a TSQ ENDURA triple quadrupole mass spectrometer (both from Thermo Scientific, Reinach, Switzerland). Ionization was performed using atmospheric pressure chemical ionization. For chromatographic separation, a ClinMass analytical ion exchange phase column (part-no MS5130, Recipe Munich, Germany) was used. Chromatography was performed with a binary gradient using $0.2 \%$ formic acid in water (mobile phase A) and methanol (mobile phase B). The gradient applied used $90 \%$ mobile phase A with a flow rate of 0.25 $\mathrm{ml} / \mathrm{min}$ during 0 and $2 \mathrm{~min}, 75 \%$ mobile phase A with a flow rate of $0.3 \mathrm{ml} / \mathrm{min}$ during 2 and $4.17 \mathrm{~min}, 100 \%$ mobile phase B with a flow rate of $0.3 \mathrm{ml} / \mathrm{min}$ during 4.17 and $5.9 \mathrm{~min}$, and $90 \%$ mobile phase A with a flow rate of $0.5 \mathrm{ml} / \mathrm{min}$ during 5.9 and $8.9 \mathrm{~min}$. Theophylline-d6 (ClinMass AED, Recipe, Munich, Germany) was used as Internal Standard (IS) for all 4 analytes. For the quantification of the four analytes, the following mass transitions have been applied: caffeine $195.07 \rightarrow 151.04 \mathrm{~m} / \mathrm{z}$, paraxanthine $181.08 \rightarrow 69.26 \mathrm{~m} / \mathrm{z}$, theobromine $181.12 \rightarrow 135.11 \mathrm{~m} / \mathrm{z}$, theophylline $181.08 \rightarrow 124.11 \mathrm{~m} / \mathrm{z}$, and theophylline-d6 187.15 $\rightarrow 146.16$, respectively. Twenty microliters from the clear top layer of the centrifuged saliva samples were mixed with 10 $\mu \mathrm{l}$ of IS and $100 \mu \mathrm{l}$ of mobile phase A. After centrifugation for $5 \mathrm{~min}$ at $16,300 \mathrm{~g}$, the clear top layer was transferred to an autosampler vial. Calibrators have been prepared in blank saliva from a caffeine-abstinent volunteer within the range of $40-8,000 \mathrm{ng} / \mathrm{ml}$ for caffeine and $20-10,000 \mathrm{ng} / \mathrm{ml}$ for the other analytes. The two quality control samples, also prepared in blank saliva from a caffeine-abstinent volunteer, had a concentration of 300 and $3,000 \mathrm{ng} / \mathrm{ml}$ for caffeine, and 150 and $1,500 \mathrm{ng} / \mathrm{ml}$ for the other analytes.

We used the samples in the caffeine condition to calculate the kinetics of caffeine and paraxanthine by peak level (Cmax), peak time (Tmax), elimination rates $\left(\mathrm{K}_{\mathrm{el}}\right)$, and half-lives. In addition, we characterized the accumulation of caffeine and paraxanthine by the AUC in the caffeine condition (AUCc) and the caffeine deprivation (AUCw). Furthermore, we examined the overnight residuals of each compound in the caffeine condition in the morning, right before the first treatment on day 10. This level indicated the progress of the elimination of caffeine and paraxanthine during the repetition of daily intake. Cmax was defined by the maximal level after the last caffeine administration, and the latency to Cmax (hours after the last intake) was used as Tmax. Due to the sampling frequency, the earliest sample collected after the last administration was roughly by $105 \mathrm{~min}$, which limited the quantification of the variances of Cmax and Tmax below this threshold. A half-life was defined by the time from the peak to the time when the concentration approximates $50 \%$ of the maximal level $\left(\mathrm{C}_{50}\right)$. AUC of caffeine and paraxanthine was calculated with the trapezoidal rule over the 11 samples separately per caffeine condition and acute caffeine deprivation.

\section{Gray Matter and Cerebral Blood Flow}

T1-weighted structural data were obtained with a MagnetizationPrepared Rapid Gradient Echo (MP-RAGE) sequence $(1 \times 1$ $\left.\times 1 \mathrm{~mm}^{3}, \mathrm{TR}=2,000 \mathrm{~ms}, \mathrm{TE}=3.37 \mathrm{~ms}, \mathrm{FA}=8^{\circ}\right)$ on a $3 \mathrm{~T}$ Siemens scanner (MAGNETOM Prisma; Siemens Healthineers, Erlangen, Germany). CBF was measured by 2D Echo-Planar Imaging pulsed arterial spin labeling sequence $\left(4 \times 4 \times 4 \mathrm{~mm}^{3}\right.$, $\mathrm{TR}=3,000 \mathrm{~ms}, \mathrm{TE}=12 \mathrm{~ms}, \mathrm{FA}=90$ ). For the detailed pipeline of preprocessing and the whole-brain analyses (WBAs), please find the methods in Lin et al. (21). The current analysis adopted a region-of-interest (ROI) approach based on the previously reported caffeine-induced results in a WBA (21). The pre-defined regions are the right hippocampus for GM, and precuneus, thalamus, and basal ganglia for CBF. We extracted the mean intensity of GM (indicating both volume and density of GM) and the mean quantity of $\mathrm{CBF}$ in the respective ROIs in all three conditions and examined the recovery status after $36 \mathrm{~h}$ of caffeine deprivation compared to placebo and caffeine conditions.

\section{Statistical Analysis}

All the statistics were conducted on R ( $\mathrm{R}$ core team, Vienna, Austria). To analyze the interaction effect between condition $\mathrm{x}$ time in caffeine and paraxanthine as well as the condition effects in the regional intensity of GM and CBF, we first estimated the coefficients of condition effects with a generalized linear mixed model by the afex package (28), followed by ANOVA to obtain the statistical parameters of variance analysis (F, T, and p-values). Post-hoc pairwise analysis was 


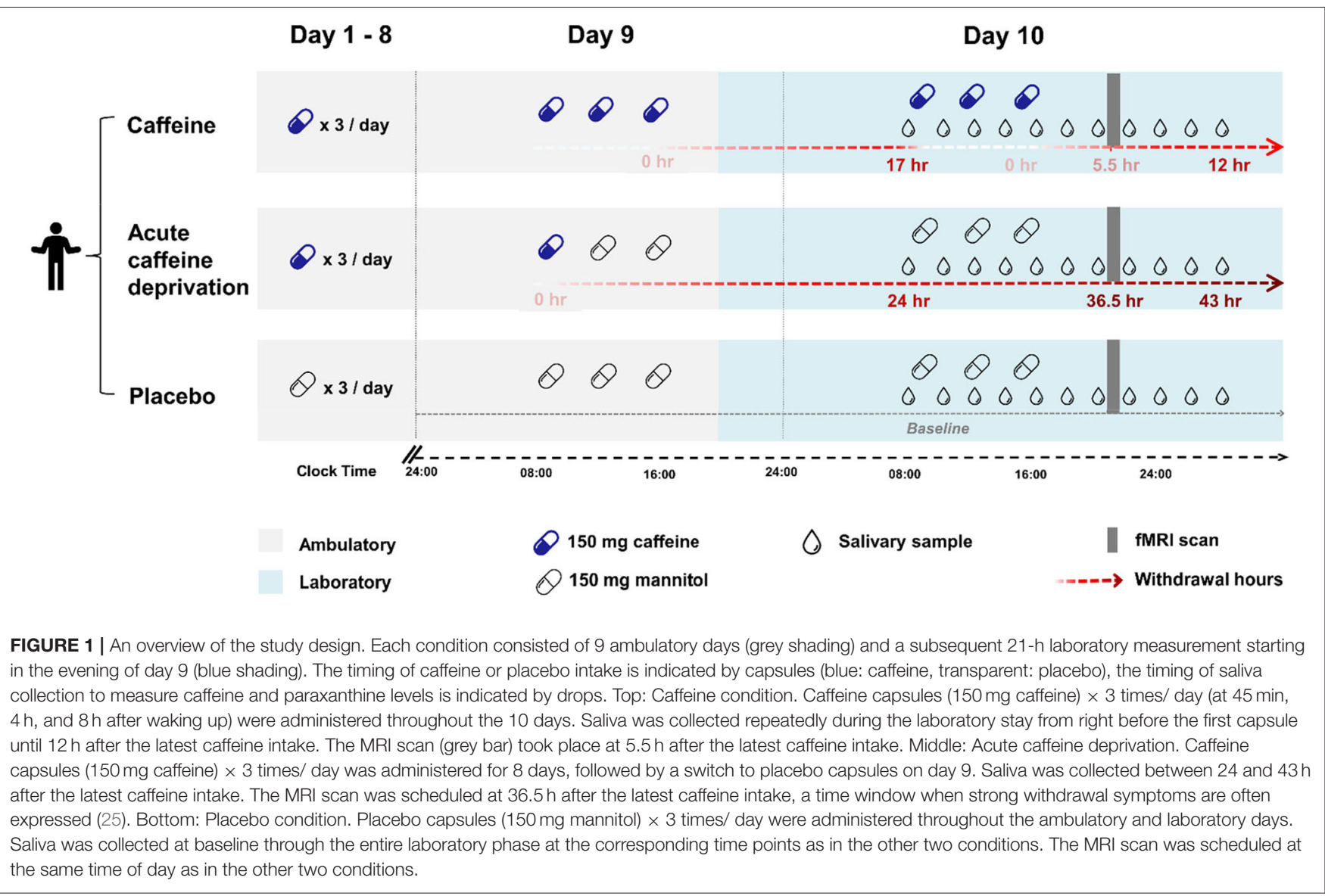

performed by using Tukey's multiple comparison test. The interindividual analyses on associations between doses (including habitual caffeine intake and treatment dose) and half-lives of caffeine and paraxanthine were performed by generalized linear regressions.

\section{RESULTS}

\section{Forty-Three Hours Profiles and Pharmacokinetics}

Twenty volunteers (age: $26.4 \pm 4.0$ years; BMI: $22.7 \pm 1.4$ $\mathrm{kg} / \mathrm{m}^{2}$; weights: $76.2 \pm 8.7 \mathrm{~kg}$; relative dosage of laboratory treatment: $6.0 \pm 0.6 \mathrm{mg} / \mathrm{kg} / \mathrm{day}$; and self-reported habitual caffeine intake: $6.8 \pm 2.3 \mathrm{mg} / \mathrm{kg} /$ day) completed the study. We present the 43-h profile of caffeine and paraxanthine in Figure 2, and the exhaustive data of all samples in three conditions are included in the supplement (Supplementary Table 1). The significant main effect of condition $\left[F_{(2,602)}=618.0, p<0.001\right]$ on salivary levels of caffeine indicated overall higher levels in the caffeine condition $(t=30.5, p<0.001)$ compared to placebo. The overall levels of caffeine in the condition of caffeine deprivation were significantly lower compared to caffeine condition $(t=-28.7, p<0.001)$ but did not significantly differ from placebo $(t=1.7, p=0.190)$. Indicated by the condition $\mathrm{x}$ sample interaction $\left[F_{(10,602)}=9.3, p<0.001\right]$, the overnight residual level of caffeine already before the first laboratory intake in the caffeine condition was significantly higher than in the placebo condition (see $17 \mathrm{~h}$ after the latest intake in Figure 2, $t=3.6, p<0.001)$. Caffeine levels in the caffeine condition remained higher than in the placebo condition until $12 \mathrm{~h}$ after the latest intake $(t=5.3$, $p<0.001)$.

Regarding the salivary levels of paraxanthine, we also observed a significant main effect of condition $\left[F_{(2,602)}=400.4, p<0.001\right]$. Post-hoc analysis indicated that the paraxanthine levels were significantly higher in the caffeine $(t=25, p<0.001)$ than in the placebo condition, while in the condition of caffeine deprivation, the levels were massively reduced $(t=-21.7$, $p<0.001$, compared to caffeine) but still significantly higher than in placebo condition $(t=3.8, p<0.001)$. Furthermore, indicated by the condition $\mathrm{x}$ sample interaction $\left[F_{(10,602)}=2.0\right.$, $p=0.007]$, the overnight residual level of paraxanthine before the first laboratory intake in the caffeine condition was significantly higher than in the placebo condition $(t=5.4$, $p<0.001)$. The paraxanthine levels remained higher than in the placebo condition after $12 \mathrm{~h}$ after the last intake $(t=6.9$, $p<0.001)$.

As presented in Table 1, paraxanthine peaked $3.2 \mathrm{~h}$ later than caffeine $(t=3.8, p=0.002)$ and had a $3.5 \mathrm{~h}$ longer half-life than 


\section{A Caffeine and paraxanthine concentrations on the laboratory day (Day 10)}
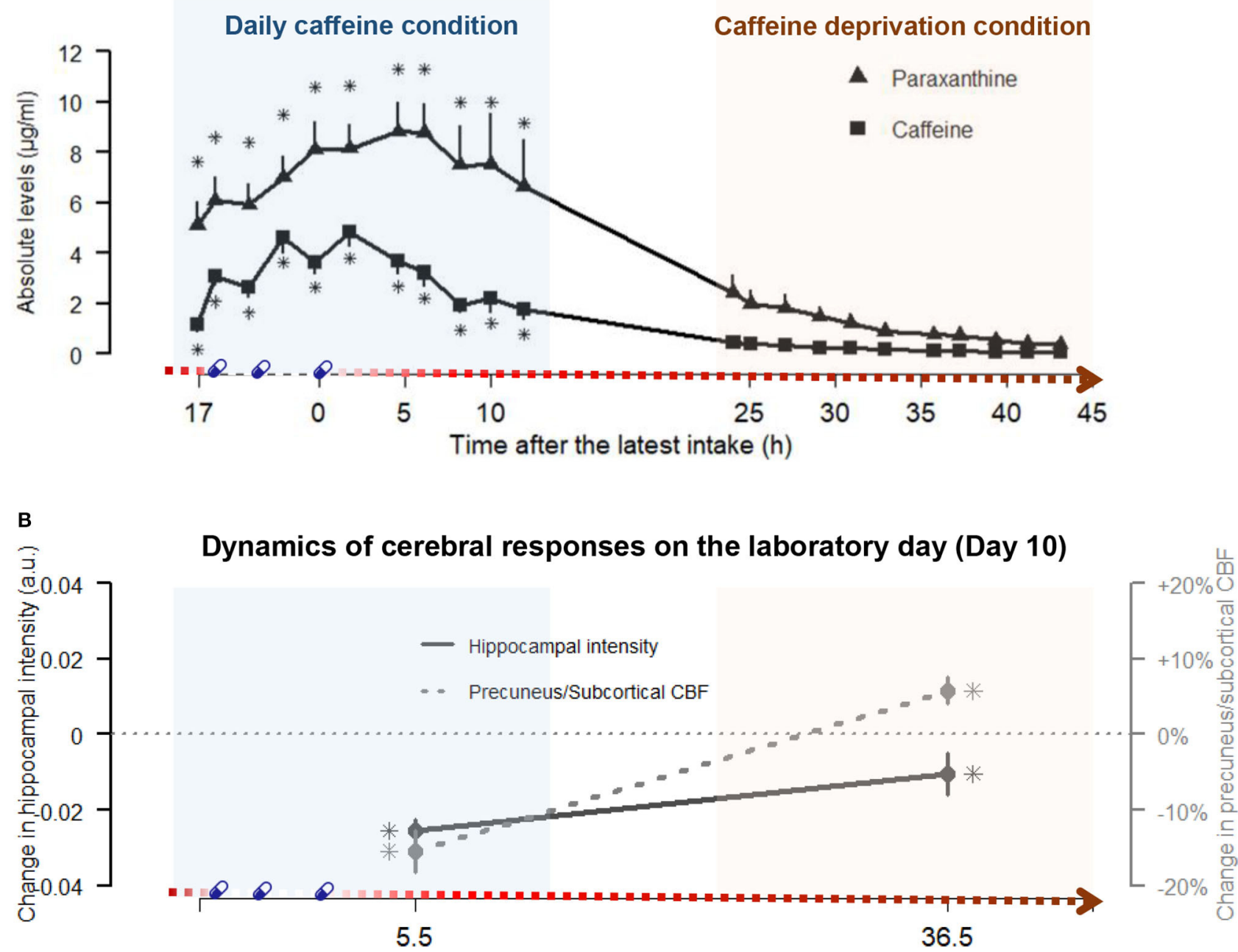

Time after the latest intake $(h)$

FIGURE 2 | The paraxanthine and caffeine concentrations at the respective time points and the dynamics of cerebral responses on the laboratory day (day 10) in daily caffeine and caffeine deprivation conditions, respectively. (A) juxtaposes the profiles of caffeine (squares) and paraxanthine (triangle) in caffeine condition (blue shading, left panel) and after the caffeine deprivation (red shading, right panel) against the duration after the latest dose of caffeine on the $x$-axis. Echoing Figure 1, the gradient red arrow parallel to the $\mathrm{x}$-axis schematically indicates the duration of the caffeine deprivation. The times of treatments are denoted by blue capsules. Detailed statistics are addressed in the Result section. In brief, the main effects of conditions indicated that paraxanthine levels remained elevated throughout the caffeine and the caffeine deprivation conditions compared to placebo, while caffeine levels were elevated in caffeine conditions but did not significantly differ from placebo in the deprivation. Asterisks (*) indicated the time points exhibiting significantly elevated levels compared to placebo by a post-hoc analysis on the significant Condition $\mathrm{x}$ Sample interaction. (B) illustrates the magnitudes of the changes in hippocampal GM intensity (straight line) and the precuneus + subcortical CBF quantity (dashed line) during daily caffeine intake and after caffeine deprivation, relative to placebo (dotted horizontal line). The asterisks indicated significant differences compared to placebo. Detailed statistics are addressed in the Results section.

caffeine $(t=2.7, p=0.15)$. Furthermore, after correcting for the false discovery (reported in $q$ values), the regression coefficients (Figure 3) indicated that higher habitual intake was significantly associated with shorter half-life of caffeine $(\beta=-0.11, p=0.002$, $q=0.006)$ and of paraxanthine $(\beta=-0.14, p=0.04, q=0.04)$, as well as at trend associated with the larger disproportionality between paraxanthine and caffeine (AUCc of PX/AUCc of CA: $\beta=0.05, p=0.036, q=0.054$ ).

\section{Brain Recovery at $36.5 \mathrm{~h}$ of Caffeine Deprivation}

As illustrated by Figure 2, the reduced hippocampal GM during daily caffeine intake reported earlier elsewhere (21) remained significantly lower after $36.5 \mathrm{~h}$ of caffeine deprivation compared to the placebo condition $\left(t_{\mathrm{W}-\mathrm{P}}=-2.1\right.$, $\left.p_{\mathrm{W}-\mathrm{P}}=0.039\right)$. The magnitude, however, was reduced after $36.5 \mathrm{~h}$ deprivation compared to the caffeine condition 
TABLE 1 | Peak level, peak time, half-life, and morning residuals of caffeine and paraxanthine during the caffeine condition.

\begin{tabular}{|c|c|c|c|c|c|c|c|}
\hline & \multicolumn{2}{|c|}{ Median (interquartile range) } & \multicolumn{5}{|c|}{ Mean \pm SD (max.-min.) } \\
\hline & Peak time $^{\text {a }}$ (h) & Half-life (h) & $\mathbf{K}_{\mathrm{el}}$ & $\begin{array}{l}\text { Peak level } \\
(\mu \mathrm{g} / \mathrm{ml})\end{array}$ & $\begin{array}{l}\text { Overnight residual } \\
\qquad(\mu \mathrm{g} / \mathrm{ml})\end{array}$ & $\begin{array}{c}\mathrm{AUC}_{\mathrm{C}} \\
\left(\mu \mathrm{g}^{\star} \mathrm{h} / \mathrm{ml}\right)^{\bar{\tau}}\end{array}$ & $\begin{array}{c}\mathrm{AUC}_{\mathrm{W}} \\
\left(\mu \mathrm{g}^{\star} \mathrm{h} / \mathrm{ml}\right)^{\bar{\tau}}\end{array}$ \\
\hline Caffeine & $1.75\left(1.75^{\mathrm{a}}-1.75\right)$ & $4.33(4.33-7.79)$ & $\begin{array}{l}0.14 \pm 0.05 \\
(0.07-0.24)\end{array}$ & $\begin{array}{l}5.2 \pm 2.2 \\
(3.0-11.2)\end{array}$ & $\begin{array}{l}1.2 \pm 1.2 \\
(0.02-4.8)\end{array}$ & $\begin{array}{l}36.1 \pm 18.6 \\
(18.2-85.0)\end{array}$ & $\begin{array}{l}2.4 \pm 3.5 \\
(0.2-13.3)\end{array}$ \\
\hline Paraxanthine & $4.58\left(1.75^{\mathrm{a}}-6.08\right)$ & $7.79(4.60-13.10)$ & $\begin{array}{c}0.12 \pm 0.10 \\
(0.03-0.36)\end{array}$ & $\begin{array}{l}11.2 \pm 8.5 \\
(5.4-42.3)\end{array}$ & $\begin{array}{c}5.2 \pm 4.0 \\
(0.056-15.2)\end{array}$ & $\begin{array}{l}84.8 \pm 51.8 \\
(37.4-241.8)\end{array}$ & $\begin{array}{c}13.3 \pm 16.8 \\
(0.6-63.3)\end{array}$ \\
\hline
\end{tabular}

a The earliest sample after the last intake was collected at $1.75 \mathrm{~h}$, which was therefore the possible minimum peak time.

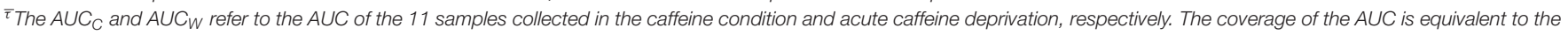
time from the first sample in the morning until $12 \mathrm{~h}$ after the last intake in the caffeine condition, and from 24 to $43 \mathrm{~h}$ after the last intake in the condition of acute caffeine deprivation.

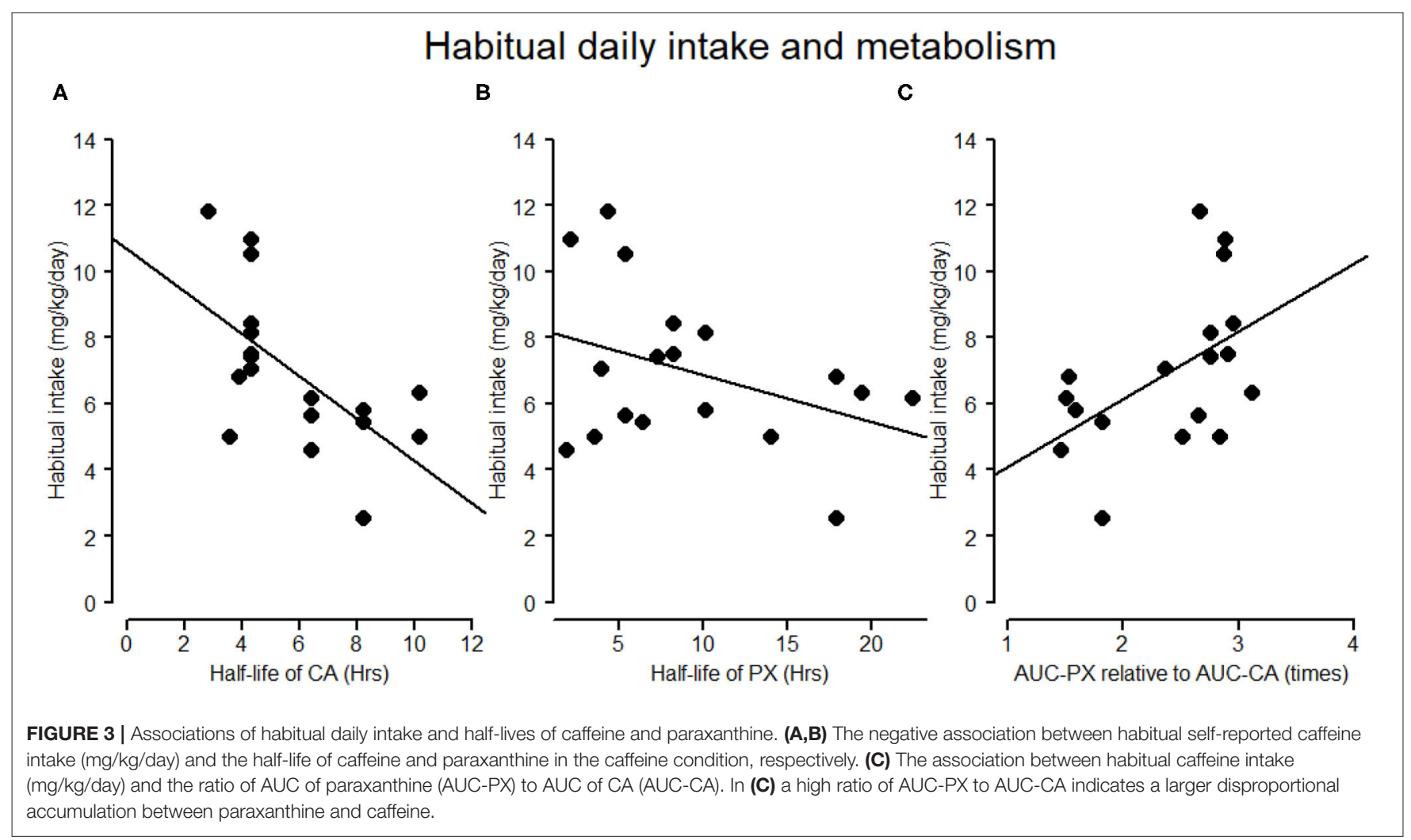

$\left(t_{\mathrm{W}-\mathrm{C}}=3.2, p_{\mathrm{W}-\mathrm{C}}=0.003\right)$. On the other hand, $\mathrm{CBF}$ in precuneus, thalamus, and basal ganglia, which was reduced during daily caffeine intake (21), was elevated at 36.5-h caffeine deprivation compared to the placebo condition $\left(t_{\mathrm{W}-\mathrm{P}}=2.1\right.$, $p_{\mathrm{W}-\mathrm{P}}=0.039$ ). In the supplement (Supplementary Figure 1), we also reported the results from the voxel-based WBA on $\mathrm{GM}$ and $\mathrm{CBF}$ after $36 \mathrm{~h}$ of caffeine deprivation compared to baseline.

\section{DISCUSSION}

The present study provides the first estimates for the kinetics of caffeine and paraxanthine and the responses of GM and CBF during and after a typical daily caffeine intake pattern [i.e., intake in the morning, at noon, and in the afternoon (1315)]. We observed elevated residuals of paraxanthine and of caffeine carried overnight during daily intake, suggesting an accumulation over repeated daily caffeine consumption. The attrend association between the habitual caffeine intake and the proportion of AUC-PX to AUC-CA indicates that people with higher habitual intake may tend to have a larger accumulation of paraxanthine during caffeine metabolism than people with a lower habitual intake. Additionally, our data allowed for the first time characterizing a recovery from daily intake after 24$43 \mathrm{~h}$ of caffeine deprivation, where the overall paraxanthine levels remained elevated. Finally, the caffeine-induced reduction in hippocampal GM intensity was only partially recovered by $36 \mathrm{~h}$ of caffeine deprivation. In contrast, CBF was significantly elevated compared to placebo. Taken together, our data suggest that 
conventional daily caffeine intake does not provide sufficient time for the elimination of caffeine and paraxanthine. Furthermore, even though the salivary caffeine nearly reaches a clear state, the caffeine-associated brain responses will require a longer time to be fully restored. Finally, the accumulation of paraxanthine entails a critical role in the effects of caffeine consumption during chronic intake. Given its high potency at the cerebral adenosine receptors (8), the potential effects of prolonged exposure to this xanthine and its clinical application should be further inspected in the future.

\section{Caffeine Metabolism, Accumulation of Paraxanthine, and Habitual Caffeine Intake: A Genetic Trait?}

Daily repeated intake of caffeine is a very common phenomenon and occurs in adults more frequently as compared to acute irregular consumption of the psychostimulant after a certain phase of abstinence [patterns of regular caffeine intake, see (14)]. Besides the present data, however, the evidence on the course of human caffeine metabolism under conditions of daily intake is scarce.

With a unified dose of $150 \mathrm{mg} \times 3 /$ day, our study had an average relative dose of $2 \mathrm{mg} / \mathrm{kg} \times 3$ times/day in a 4 -h interval. The median peak time and half-life of caffeine $(<105 \mathrm{~min})$ in this study are very similar to the acute intake reported in earlier studies (7, 29-32). However, compared to the only available study of daily intake (4), our participants exhibited much faster metabolism in caffeine and paraxanthine, which might be due to a shorter dose interval $(2 \mathrm{~h})$ in their study compared to ours ( $4 \mathrm{~h})$. The interval of $4 \mathrm{~h}$ was nearly equal to the half-life time of caffeine and thus may have reduced the iteration of the caffeine concentration over repeated intake.

The faster metabolism compared to the earlier study (4) might also reflect genetic traits in our participants, who had an average level of habitual intake level of $474.1 \pm$ $107.5 \mathrm{mg}$. Several genome-wide association studies (GWAS) have discovered the link between habitual caffeine intake and caffeine metabolism through the polymorphism of CYP1A2, AHR, and CYP2A6 (17-20). Specifically, the genetic variants of CYP1A2 and AHR associated with a lower habitual caffeine intake are also associated with slow caffeine metabolism [i.e., a higher plasma level of caffeine and lower ratios of paraxanthine to caffeine (19)]. This genetic tendency is supported by our salivary data, which showed that a lower habitual caffeine intake was associated with a longer half-life of caffeine, a longer half-life of paraxanthine, as well as a lower ratio of paraxanthine to caffeine. The elevated paraxanthine levels over the entire course might also reflect the tendency to have a fast transformation of caffeine to paraxanthine in high caffeine consumers, yet without a commensurate speed for the metabolism of paraxanthine.

As our study does not include a washout period before each ambulatory part, we cannot exclude that the accumulation of paraxanthine might have been carried over from participants' prior habitual intake. This does, however, not contradict the suggested risk for an accumulated paraxanthine concentration as a consequence of habitual or daily caffeine. A dosedisproportional elevation in paraxanthine is not limited to daily intake but can also be observed when increasing the dose of intake (33).

In summary, we observed an accumulation of paraxanthine present during a pattern of caffeine intake, which imitated a realistic dose and timing of consumption. This accumulation was further intensified in people with a higher dose of habitual caffeine consumption. Paraxanthine is considered to possess lower toxicity and anxiogenesis than caffeine and other methylxanthines $(9,34,35)$, while it can still exert similar effects as caffeine in wake-promotion (9), psychostimulation (10), elevated blood pressure, and release of epinephrine (11). Since paraxanthine levels are prone to be mounted over daily intake, understanding the cognitive and physiological outcomes during prolonged exposure to paraxanthine will clarify the long-term benefits and harms of daily caffeine intake.

\section{A Role of Habitual Caffeine Intake in the Cerebral Responses to Caffeine?}

Earlier GWAS did not support the association between variants of CYP1A2 or AHR and long-term neurocognitive performance $(17,36)$. Nonetheless, a genetic trait for the susceptibility of the cerebral responses to caffeine intake might instead lie at the ADORA2A gene. Behaviorally, the polymorphism of ADORA2A has been linked to some caffeine-induced neuropsychological responses (37-40) and is also associated with the levels of habitual caffeine intake $(37,41)$. At the synaptic level, ADORA2A is responsible for not only the expression of adenosine A2A receptors (A2AR) but also the modulation of glutamatergic signaling (42) and dopaminergic receptors (38) as well as the distributions of adenosine A1 receptors (A1R) in the emotionregulating regions, including the hippocampus (43). Adenosine $\mathrm{A} 1 \mathrm{R}$ and A2AR play counteractive roles in the hippocampal synaptic homeostasis $(44,45)$, where $\mathrm{A} 2 \mathrm{AR}$ facilitates presynaptic glutamate release while A1R modulates the postsynaptic NMDA receptors and reduces excitatory signals (44). Hence, a potential modification of A1R and A2AR expressions by a polymorphism of ADORA2A might set a predisposition for the neural responses toward the antagonist, caffeine. For instance, compared to people with $\mathrm{C}$ genotypes of ADORA2A, ADORA2A T/T allele carriers had higher average levels of habitual caffeine intake and a higher susceptibility to the anxiogenic effect of caffeine as well as an increased expression of A1R in frontal, hippocampal, and entorhinal cortices (43). As moderate-to-high caffeine consumers, our participants might bear the genetic propensity to have stronger responses toward A1R antagonism by caffeine, which might pose a disposition to hippocampal plasticity or excitotoxicity. Future studies are therefore recommended to include a wider range of habitual caffeine consumers or collect genetic information for better precision.

To date, there is no direct evidence on the link between ADORA2A and caffeine-induced hippocampal plasticity or CBF in healthy humans. It has been found, however, that the variants of ADORA2A were associated with the degeneration of hippocampal gray matter in both schizophrenic patients (46) 
and aging populations with cognitive decline (42). Adding to this point, the frequently reported association between lifetime caffeine intake and a reduced risk for cognitive decline (47-50) or neurodegeneration (51-53) could be driven by a common genetic factor. Our results ad to this point that at least in a certain population-potentially consumers who naturally accommodate to moderate habitual caffeine consumption-a daily intake of moderate-dose caffeine might instead increase the risk for a reduction in hippocampal gray matter.

\section{Do We Sufficiently Recover During Daily Caffeine Intake?}

Withdrawal responses commonly occur after discontinuing regular caffeine intake. While our reports elsewhere have discussed in detail the implications of cerebral effects of caffeine $(21,54)$, the current analyses further added that these changes might take longer than the interval of day-to-day intakes to recover. We corroborated the caffeine cessation-induced vasodilation by the elevated CBF (55-60). An increased CBF, which could be attributed to the enhanced adenosine-modulated vasodilation after chronic caffeine exposure (61-63), was also frequently observed during increased sleep pressure, such as in the evening compared to morning (26), after sleep restriction (64), and after sleep deprivation (26). In line with the literature, the cognitive responses in the same volunteers reported elsewhere, including reduced vigilance, increased sleepiness, and enhanced sleep depth $(24,65)$, confirmed that the participants were experiencing a solid withdrawal state.

Responses toward an acute caffeine deprivation can manifest as a restoration of adapted neural functioning when caffeine intake is ceased. The molecular mechanism of such adaptations includes a mounting concentration of extracellular endogenous adenosine (61) and upregulated adenosine receptors (6668). Both mechanisms can lead to a surge of cognitive and physiological reactions through the strengthened adenosine binding. These reactions include fatigue, reduced concentration, mood disturbance, headache, as well as increased vasodilation as addressed $(25,69,70)$. Intense withdrawal symptoms are usually perceived around 20 and $50 \mathrm{~h}$ after the last regular intake and, in extreme cases, can last maximal 9 days (25). The earliest observed neurovascular responses to caffeine deprivation in existing evidence were at $21 \mathrm{~h} \mathrm{(58).}$

While combating withdrawal symptoms are often the reason to consolidate the daily repeated consumption of caffeine (71), the typical daily repeated caffeine intake, however, is unlikely to provide enough time for a full "withdrawal-driven restoration." The first evidence comes from our observation in the overnight residuals of caffeine and paraxanthine levels, which were measured at $17 \mathrm{~h}$ after the last intake. Furthermore, during the $24-43 \mathrm{~h}$ of caffeine deprivation when the caffeine levels were nearly cleared, the paraxanthine levels remained elevated. In other words, a repetition of intake shorter than this time window is most likely to be insufficient for the full elimination of both caffeine and paraxanthine. The prolonged presence of high levels of such adenosine antagonists may impede the neural homeostasis dependent on the activations of adenosine receptors. In neurogenesis of adult rodents, the presence of a similar dose of caffeine during sleep has been shown to suppress the cell proliferation in the hippocampus [(72); Dose conversion: $10 \mathrm{mg} / \mathrm{kg}$ in rodents were estimated to be equivalent to $250 \mathrm{mg} / 70 \mathrm{~kg}$ in humans (71)]. The concurrence of a reduced hippocampal GM intensity and an incomplete caffeine elimination, together with a GM recovery after being deprived of caffeine, underscore the importance of a sufficient cessation period. The overcompensation of the CBF response after the caffeine deprivation, again, points to a longer time, perhaps some consecutive days, for full recovery. Future studies should confirm this postulation with a design which allows full elimination caffeine and paraxanthine as well as an observation of the response in cerebral morphology.

\section{LIMITATIONS}

This study bears a few limitations which should be carefully taken into account. First, as discussed earlier, the current analysis leveraged the data collected in a study without a washout period before the start of ambulatory treatment. This may limit the precise attribution of observed metabolic outcomes to the doses and durations of laboratory treatment. However, it did not completely compromise our interpretation of the impacts of the habitual intake, as the variations of the habitual intake levels were restricted by the selection criterion and are comparable to laboratory caffeine intake (300-600 mg/day, average $474.1 \pm 107.5 \mathrm{mg} /$ day). Second, one might consider the dose administered in our study ( $150 \mathrm{mg} 3$ times daily) to be rather high. Earlier studies reported an average caffeine intake per capita varying from 16 to $400 \mathrm{mg} /$ day per capita worldwide $(71,73)$. However, this number can be underestimated in regular consumers by taking the non-consumers to average (73). Furthermore, while consumption of coffee and tea were the primary target of many large-scale country-wise surveys, some other caffeinated products are often missing, such as cola, chocolate, and energy drinks, which could also lead to an underestimation. Thus, the outcomes in our study derived from $450 \mathrm{mg}$ of daily intake may be particularly of interest to the regular consumers, especially those who may consume multiple types of caffeinated products. On the other hand, one might consider that quantifying habitual caffeine levels by self-reports may not be accurate, yet earlier studies have repeatedly reported generally good reliabilities between self-report caffeine intake and salivary concentrations of caffeine and paraxanthine unless the self-report amount is $>600 \mathrm{mg} /$ day $(74,75)$. In addition, one might consider our sample size to be relatively small despite a within-subject design. Our sample size calculations were indeed based on reported effect sizes of caffeine intake mainly on sleep-wake regulatory indices. Furthermore, we attempted to reduce the variance derived from the sex differences by only including male participants. Thus, the generalizability of the outcomes to female caffeine consumers is limited. Finally, due to a convenient advantage taken from an existing study, the sampling timing of salivary concentrations may not be optimal, especially a relatively later first sample after the caffeine intake 
( $\sim 105 \mathrm{~min}$ ). This can potentially bias the calculation of kinetics. It is of importance to note that the kinetics of caffeine are rather comparable to the earlier evidence as discussed previously. Paraxanthine, on the other hand, did not suffer from this issue, as its concentration peaked much later than the earliest sample after the caffeine intake. Finally, future studies may continue the dynamic perspective and precisely illustrate dose-dependent changes in the metabolism of caffeine and paraxanthine from both salivary and plasma samples in healthy populations.

\section{SIGNIFICANCE}

Caffeine is consumed on a daily basis among $80 \%$ of the worldwide population (73). It is of importance to beware that daily consumption, even merely in the daytime, can accumulate exposure to the psychostimulant and prevents the body from full recovery. The in-progress recovery from a reduced GM and the elevated CBF after $36 \mathrm{~h}$ of caffeine cessation entails a longer time required for full restoration than the conventional repetition of daily intake. On the other hand, the accumulation in paraxanthine underscores the importance to investigate its cognitive and physiological effects, which may be responsible for long-term outcomes of chronic exposure to caffeine. Methodologically, the adapted metabolism also suggests a careful consideration to translate acute effects of caffeine onto daily usage. Finally, the responses of GM and $\mathrm{CBF}$ in both the caffeine condition and after $36 \mathrm{~h}$ of caffeine deprivation emphasize the importance of restricting caffeine intake when studying cerebral morphometry and neurovascular activities.

\section{DATA AVAILABILITY STATEMENT}

The raw data supporting the conclusions of this article will be made available by the authors, without undue reservation.

\section{ETHICS STATEMENT}

The studies involving human participants were reviewed and approved by Ethics Committee Northwest/Central

\section{REFERENCES}

1. Blanchard J, Sawers SJ. The absolute bioavailability of caffeine in man. Eur J Clin Pharmacol. (1983) 24:93-8. doi: 10.1007/BF00613933

2. Arnaud MJ. Metabolism of caffeine and other components of coffee. In: Garattini SE, editor. Caffeine, Coffee and Health. New York, NY: Raven Press (1993). p. 43-95.

3. Kaplan GB, Greenblatt DJ, Ehrenberg BL, Goddard JE, Cotreau MM, Harmatz JS, et al. Dose-dependent pharmacokinetics and psychomotor effects of caffeine in humans. J Clin Pharmacol. (1997) 37:693-703. doi: 10.1002/j.1552-4604.1997.tb04356.x

4. Denaro CP, Brown CR, Wilson M, Jacob P, Benowitz NL. Dose-dependency of caffeine metabolism with repeated dosing. Clin Pharmacol Ther. (1990) 48:277-85. doi: 10.1038/clpt.1990.150

5. Nehlig A. Interindividual differences in caffeine metabolism and factors driving caffeine consumption. Pharmacol Rev. (2018) 70:384-411. doi: 10.1124/pr.117.014407
Switzerland (approval reference: EKNZ 2016-00376). The patients/participants provided their written informed consent to participate in this study.

\section{AUTHOR CONTRIBUTIONS}

Y-SL: data acquisition, analysis, and drafting the manuscript and figures. JW: data acquisition. H-PL: conception of the study. FS: design of the study. CG: data acquisition and medical consultant. JK and SR: measurement of salivary samples. KR: measurement of salivary samples and supervisor. SB: design of the study and supervisor. CC: conception and design of the study. CR: conception and design of the study and drafting the manuscript. All authors contributed to the article and approved the submitted version.

\section{FUNDING}

This study was supported by Swiss National Science Foundation (grant 320030-163058).

\section{ACKNOWLEDGMENTS}

We express our sincere appreciation to our interns Andrea Schumacher and Laura Tincknell, M.Sc. student Sven Leach, as well as all the study helpers for their assistance in the experiment and data processing. We also thank Drs. Helen Slawik and Martin Meyer for the health check during the screening process. We especially appreciate all our participants for their volunteering and cooperation. This manuscript has been published as a preprint on bioRxiv and included in the doctoral thesis of YSL, entitled The Influence of Daily Caffeine Consumption on Human Brain Morphometry and Neurocognition at the Faculty of Medicine, University of Basel.

\section{SUPPLEMENTARY MATERIAL}

The Supplementary Material for this article can be found online at: https://www.frontiersin.org/articles/10.3389/fnut.2021. 787225/full\#supplementary-material
6. Urry E, Jetter A, Landolt HP. Assessment of CYP1A2 enzyme activity in relation to type-2 diabetes and habitual caffeine intake. Nutr Metab. (2016) 13:66. doi: 10.1186/s12986-016-0126-6

7. Arnaud MJ. Pharmacokinetics and metabolism of natural methylxanthines in animal and man. Handbook Exp Pharmacol. (2011) 200:33-91. doi: 10.1007/978-3-642-13443-2_3

8. Fredholm BB, Bättig K, Holmén J, Nehlig A, Zvartau EE. Actions of caffeine in the brain with special reference to factors that contribute to its widespread use. Pharmacol Rev. (1999) 51:83-133.

9. Okuro M, Fujiki N, Kotorii N, Ishimaru Y, Sokoloff P, Nishino S. Effects of paraxanthine and caffeine on sleep, locomotor activity, and body temperature in orexin/ataxin-3 transgenic narcoleptic mice. Sleep. (2010) 33:930-42. doi: 10.1093/sleep/33.7.930

10. Orrú M, Guitart X, Karcz-Kubicha M, Solinas M, Justinova Z, Barodia SK, et al. Psychostimulant pharmacological profile of paraxanthine, the main metabolite of caffeine in humans. Neuropharmacology. (2013) 67:47684. doi: 10.1016/j.neuropharm.2012.11.029 
11. Benowitz NL, Jacob P, 3rd, Mayan H, Denaro C. Sympathomimetic effects of paraxanthine and caffeine in humans. Clin Pharmacol Ther. (1995) 58:68491. doi: 10.1016/0009-9236(95)90025-X

12. Lau CE, Ma F, Falk JL. Oral and IP caffeine pharmacokinetics under a chronic food-limitation condition. Pharmacol Biochem Behav. (1995) 50:24552. doi: 10.1016/0091-3057(94)00306-4

13. Rochat C, Eap CB, Bochud M, Chatelan A. Caffeine consumption in switzerland: results from the first national nutrition survey $\mathrm{MenuCH}$. Nutrients. (2019) 12:28. doi: 10.3390/nu12010028

14. Martyn D, Lau A, Richardson P, Roberts A. Temporal patterns of caffeine intake in the United States. Food Chem Toxicol. (2018) 111:7183. doi: 10.1016/j.fct.2017.10.059

15. Lieberman HR, Agarwal S, Fulgoni VL, 3rd. Daily Patterns of Caffeine Intake and the Association of Intake with Multiple Sociodemographic and Lifestyle Factors in US Adults Based on the NHANES 2007-2012 Surveys. J Acad Nutr Dietetics. (2019). 119:106-14. doi: 10.1016/j.jand.2018.08.152

16. Latini R, Bonati M, Castelli D, Garattini S. Dose-dependent kinetics of caffeine in rats. Toxicol Lett. (1978) 2:267-70. doi: 10.1016/0378-4274(78)90024-3

17. Zhou A, Taylor AE, Karhunen V, Zhan Y, Rovio SP, Lahti J, et al. Habitual coffee consumption and cognitive function: a Mendelian randomization meta-analysis in up to 415,530 participants. Sci Rep. (2018) 8:7526. doi: 10.1038/s41598-018-25919-2

18. Cornelis MC, Byrne EM, Esko T, Nalls MA, Ganna A, Paynter $\mathrm{N}$, et al. Genome-wide meta-analysis identifies six novel loci associated with habitual coffee consumption. Mol Psychiatry. (2015) 20:647-56. doi: 10.1038/mp.2014.107

19. Cornelis MC, Kacprowski T, Menni C, Gustafsson S, Pivin E, Adamski J, et al. Genome-wide association study of caffeine metabolites provides new insights to caffeine metabolism and dietary caffeine-consumption behavior. Hum Mol Genet. (2016) 25:5472-82. doi: 10.1093/hmg/ddw334

20. Josse AR, Da Costa LA, Campos H, El-Sohemy A. Associations between polymorphisms in the AHR and CYP1A1-CYP1A2 gene regions and habitual caffeine consumption. Am J Clin Nutr. (2012) 96:665-71. doi: 10.3945/ajcn.112.038794

21. Lin Y-S, Weibel J, Landolt H-P, Santini F, Meyer M, Brunmair J, et al. Daily caffeine intake induces concentration-dependent medial temporal plasticity in humans: a multimodal double-blind randomized controlled trial. Cereb Cortex. (2021) 31:3096-106. doi: 10.1093/cercor/bhab005

22. Bühler E, Lachenmeier DW, Schlegel K, Winkler G. Development of a tool to assess the caffeine intake among teenagers and young adults. Ernaehrungs Umschau. (2013) 61:58-63. doi: 10.4455/eu.2014.011

23. Snel J, Lorist MM. Effects of caffeine on sleep and cognition. Prog Brain Res. (2011) 190:105-17. doi: 10.1016/B978-0-444-53817-8.00006-2

24. Weibel J, Lin YS, Landolt HP, Garbazza C, Kolodyazhniy V, Kistler J, et al. Caffeine-dependent changes of sleep-wake regulation: evidence for adaptation after repeated intake. Prog Neuropsychopharmacol Biol Psychiatry. (2020) 99:109851. doi: 10.1016/j.pnpbp.2019.109851

25. Juliano LM, Griffiths RR. A critical review of caffeine withdrawal: empirical validation of symptoms and signs, incidence, severity, and associated features. Psychopharmacology. (2004) 176:1-29. doi: 10.1007/s00213-004-2000-x

26. Elvsåshagen $\mathrm{T}$, Mutsaerts $\mathrm{HJ}$, Zak N, Norbom LB, Quraishi $\mathrm{SH}$, Pedersen $\mathrm{P}$, et al. Cerebral blood flow changes after a day of wake, sleep, and sleep deprivation. Neuroimage. (2019) 186:497-509. doi: 10.1016/j.neuroimage.2018.11.032

27. Killgore WD, Schwab ZJ, Kipman M, DelDonno SR, Weber M. Voxel-based morphometric gray matter correlates of daytime sleepiness. Neurosci Lett. (2012) 518:10-3. doi: 10.1016/j.neulet.2012.04.029

28. Henrik Singmann BB, Westfall J, Aust F, Ben-Shachar MS. afex: Analysis of Factorial Experiments. (2019). Available online at: https://github.com/ singmann/afex

29. Landolt HP, Werth E, Borbely AA, Dijk DJ. Caffeine intake (200 mg) in the morning affects human sleep and EEG power spectra at night. Brain Res. (1995) 675:67-74. doi: 10.1016/0006-8993(95)00040-W

30. Landolt HP, Dijk DJ, Gaus SE, Borbely AA. Caffeine reduces low-frequency delta activity in the human sleep EEG. Neuropsychopharmacology. (1995) 12:229-38. doi: 10.1016/0893-133X(94)00079-F

31. Landolt HP, Retey JV, Tonz K, Gottselig JM, Khatami R, Buckelmuller I, et al. Caffeine attenuates waking and sleep electroencephalographic markers of sleep homeostasis in humans. Neuropsychopharmacology. (2004) 29:19339. doi: 10.1038/si.npp.1300526

32. Arnaud MJ. The pharmacology of caffeine. Prog Drug Res. (1987) 31:273313. doi: 10.1007/978-3-0348-9289-6_9

33. Bortolotti A, Jiritano L, Bonati M. Pharmacokinetics of paraxanthine, one of the primary metabolites of caffeine, in the rat. Drug Metab Dispos. (1985) 13:227-31.

34. Stavric B. Methylxanthines: toxicity to humans. 3. Theobromine, paraxanthine and the combined effects of methylxanthines. Food Chem Toxicol. (1988). 26:725-33. doi: 10.1016/0278-6915(88)90073-7

35. Boison D. Methylxanthines, seizures, and excitotoxicity. Handbook Exp Pharmacol. 2011:251-66. doi: 10.1007/978-3-642-13443-2_9

36. Cornelis MC, Weintraub S, Morris MC. Caffeinated coffee and tea consumption, genetic variation and cognitive function in the uk biobank. $J$ Nutr. (2020) 150:2164-74. doi: 10.1093/jn/nxaa147

37. Rogers PJ, Hohoff C, Heatherley SV, Mullings EL, Maxfield PJ, Evershed RP, et al. Association of the anxiogenic and alerting effects of caffeine with ADORA2A and ADORA1 polymorphisms and habitual level of caffeine consumption. Neuropsychopharmacology. (2010) 35:1973-83. doi: 10.1038/npp.2010.71

38. Childs E, Hohoff C, Deckert J, Xu K, Badner J, de Wit H. Association between ADORA2A and DRD2 polymorphisms and caffeine-induced anxiety. Neuropsychopharmacology. (2008) 33:2791-800. doi: 10.1038/npp.2008.17

39. Retey JV, Adam M, Khatami R, Luhmann UF, Jung HH, Berger W, et al. A genetic variation in the adenosine A2A receptor gene (ADORA2A) contributes to individual sensitivity to caffeine effects on sleep. Clin Pharmacol Ther. (2007) 81:692-8. doi: 10.1038/sj.clpt.6100102

40. Clark I, Landolt HP. Coffee, caffeine, and sleep: a systematic review of epidemiological studies and randomized controlled trials. Sleep Med Rev. (2017) 31:70-8. doi: 10.1016/j.smrv.2016.01.006

41. Cornelis MC, El-Sohemy A, Campos H. Genetic polymorphism of the adenosine A2A receptor is associated with habitual caffeine consumption. Am J Clin Nutr. (2007) 86:240-4. doi: 10.1093/ajcn/86.1.240

42. Horgusluoglu-Moloch E, Nho K, Risacher SL, Kim S, Foroud T, Shaw LM, et al. Targeted neurogenesis pathway-based gene analysis identifies ADORA2A associated with hippocampal volume in mild cognitive impairment and Alzheimer's disease. Neurobiol Aging. (2017) 60:92-103. doi: 10.1016/j.neurobiolaging.2017.08.010

43. Hohoff C, Garibotto V, Elmenhorst D, Baffa A, Kroll T, Hoffmann A, et al. Association of adenosine receptor gene polymorphisms and in vivo adenosine A1 receptor binding in the human brain. Neuropsychopharmacology. (2014) 39:2989-99. doi: 10.1038/npp.2014.150

44. Martins RS, Rombo DM, Gonçalves-Ribeiro J, Meneses C, Borges-Martins VPP, Ribeiro JA, et al. Caffeine has a dual influence on NMDA receptormediated glutamatergic transmission at the hippocampus. Purinergic Signal. (2020) 16:503-18. doi: 10.1007/s11302-020-09724-z

45. Rebola N, Rodrigues RJ, Lopes LV, Richardson PJ, Oliveira CR, Cunha RA. Adenosine $\mathrm{A} 1$ and $\mathrm{A} 2 \mathrm{~A}$ receptors are co-expressed in pyramidal neurons and co-localized in glutamatergic nerve terminals of the rat hippocampus. Neuroscience. (2005) 133:79-83. doi: 10.1016/j.neuroscience.2005.01.054

46. Jagannathan K, Calhoun VD, Gelernter J, Stevens MC, Liu J, Bolognani F, et al. Genetic associations of brain structural networks in schizophrenia: a preliminary study. Biol Psychiatry. (2010) 68:657-66. doi: 10.1016/j.biopsych.2010.06.002

47. Vercambre MN, Berr C, Ritchie K, Kang JH. Caffeine and cognitive decline in elderly women at high vascular risk. J Alzheimers Dis. (2013) 35:41321. doi: 10.3233/JAD-122371

48. Arab L, Biggs ML, O'Meara ES, Longstreth WT, Crane PK, Fitzpatrick AL. Gender differences in tea, coffee, and cognitive decline in the elderly: the cardiovascular health study. J Alzheimers Dis. (2011) 27:55366. doi: 10.3233/JAD-2011-110431

49. van Gelder BM, Buijsse B, Tijhuis M, Kalmijn S, Giampaoli S, Nissinen A, et al. Coffee consumption is inversely associated with cognitive decline in elderly European men: the FINE study. Eur J Clin Nutr. (2007) 61:22632. doi: 10.1038/sj.ejcn.1602495

50. Ritchie K, Carrière I, de Mendonca A, Portet F, Dartigues JF, Rouaud $\mathrm{O}$, et al. The neuroprotective effects of caffeine: a prospective population study (the Three City Study). 
Neurology. (2007) 69:536-45. doi: 10.1212/01.wnl.0000266670.35 $219.0 \mathrm{c}$

51. Eskelinen MH, Ngandu T, Tuomilehto J, Soininen H, Kivipelto M. Midlife coffee and tea drinking and the risk of late-life dementia: a population-based CAIDE study. J Alzheimers Dis. (2009) 16:85-91. doi: 10.3233/JAD-2009-0920

52. Tomata Y, Sugiyama K, Kaiho Y, Honkura K, Watanabe T, Zhang S, et al. Green tea consumption and the risk of incident dementia in elderly japanese: the ohsaki cohort 2006 Study. Am J Geriatr Psychiatry. (2016) 24:881-9. doi: 10.1016/j.jagp.2016.07.009

53. Lindsay J, Laurin D, Verreault R, Hébert R, Helliwell B, Hill GB, et al. Risk factors for alzheimer's disease: a prospective analysis from the canadian study of health and aging. Am J Epidemiol. (2002) 156:44553. doi: 10.1093/aje/kwf074

54. Lin Y-S, Weibel J, Landolt H-P, Santini F, Slawik H, Borgwardt $S$, et al. Working memory performance after daily caffeine intake: compromised performance and reduced hippocampal activity. bioRxiv. 2021:2021.04.19.440520. doi: 10.1101/2021.04.19.440520

55. Sigmon SC, Herning RI, Better W, Cadet JL, Griffiths RR. Caffeine withdrawal, acute effects, tolerance, and absence of net beneficial effects of chronic administration: cerebral blood flow velocity, quantitative EEG, and subjective effects. Psychopharmacology. (2009) 204:573-85. doi: 10.1007/s00213-009-1489-4

56. Addicott MA, Yang LL, Peiffer AM, Burnett LR, Burdette JH, Chen MY, et al. The effect of daily caffeine use on cerebral blood flow: how much caffeine can we tolerate? Hum Brain Mapp. (2009) 30:3102-14. doi: 10.1002/hbm.20732

57. Mathew RJ, Wilson WH. Caffeine consumption, withdrawal and cerebral blood flow. Headache (1985) 25:3059. doi: 10.1111/j.1526-4610.1985.hed2506305.x

58. Jones HE, Herning RI, Cadet JL, Griffiths RR. Caffeine withdrawal increases cerebral blood flow velocity and alters quantitative electroencephalography (EEG) activity. Psychopharmacology. (2000) 147:371-7. doi: 10.1007/s002130050005

59. Watson J, Deary I, Kerr D. Central and peripheral effects of sustained caffeine use: tolerance is incomplete. Br J Clin Pharmacol. (2002) 54:4006. doi: 10.1046/j.1365-2125.2002.01681.x

60. Couturier EG, Laman DM, van Duijn MA, van Duijn H. Influence of caffeine and caffeine withdrawal on headache and cerebral blood flow velocities. Cephalalgia. (1997) 17:188-90. doi: 10.1046/j.1468-2982.1997.1703 188.x

61. Conlay LA, Conant JA, deBros F, Wurtman R. Caffeine alters plasma adenosine levels. Nature. (1997) 389:136. doi: 10.1038/38160

62. Al-Mashhadi RH, Skott O, Vanhoutte PM, Hansen PB. Activation of A(2) adenosine receptors dilates cortical efferent arterioles in mouse. Kidney Int. (2009) 75:793-9. doi: 10.1038/ki.2008.684

63. Pelligrino DA, Xu HL, Vetri F. Caffeine and the control of cerebral hemodynamics. J Alzheimers Dis. (2010) 20(Suppl. 1):S51-62. doi: 10.3233/JAD-2010-091261

64. Poudel GR, Innes CR, Jones RD. Cerebral perfusion differences between drowsy and nondrowsy individuals after acute sleep restriction. Sleep. (2012) 35:1085-96. doi: 10.5665/sleep.1994

65. Weibel J, Lin YS, Landolt HP, Kistler J, Rehm S, Rentsch KM, et al. The impact of daily caffeine intake on nighttime sleep in young adult men. Sci Rep. (2021) 11:4668. doi: 10.1038/s41598-021-84088-x
66. Kaplan GB, Greenblatt DJ, Kent MA, Cotreau-Bibbo MM. Caffeine treatment and withdrawal in mice: relationships between dosage, concentrations, locomotor activity and $\mathrm{A} 1$ adenosine receptor binding. J Pharmacol Exp Ther. (1993) 266:1563-72.

67. Nikodijevic O, Jacobson KA, Daly JW. Locomotor activity in mice during chronic treatment with caffeine and withdrawal. Pharmacol Biochem Behav. (1993) 44:199-216. doi: 10.1016/0091-3057(93)90299-9

68. Elmenhorst D, Meyer PT, Winz OH, Matusch A, Ermert J, Coenen HH, et al. Sleep deprivation increases $\mathrm{A} 1$ adenosine receptor binding in the human brain: a positron emission tomography study. J Neurosci. (2007) 27:24105. doi: 10.1523/JNEUROSCI.5066-06.2007

69. James JE. Acute and chronic effects of caffeine on performance, mood, headache, and sleep. Neuropsychobiology. (1998) 38:3241. doi: $10.1159 / 000026514$

70. Juliano LM, Huntley ED, Harrell PT, Westerman AT. Development of the caffeine withdrawal symptom questionnaire: caffeine withdrawal symptoms cluster into 7 factors. Drug Alcohol Depend. (2012) 124:22934. doi: 10.1016/j.drugalcdep.2012.01.009

71. Fredholm BB, Battig K, Holmen J, Nehlig A, Zvartau EE. Actions of caffeine in the brain with special reference to factors that contribute to its widespread use. Pharmacol Rev. (1999) 51:83-133.

72. Kochman LJ, Fornal CA, Jacobs BL. Suppression of hippocampal cell proliferation by short-term stimulant drug administration in adult rats. Eur J Neurosci. (2009) 29:2157-65. doi: 10.1111/j.1460-9568.2009.06759.x

73. Heckman MA, Weil J, Gonzalez de Mejia E. Caffeine (1, 3, 7trimethylxanthine) in foods: a comprehensive review on consumption, functionality, safety, and regulatory matters. J Food Sci. (2010) 75:R77-87. doi: 10.1111/j.1750-3841.2010.01561.x

74. James JE, Bruce MS, Lader MH, Scott NR. Self-report reliability and symptomatology of habitual caffeine consumption. Br J Clin Pharmacol. (1989) 27:507-14. doi: 10.1111/j.1365-2125.1989.tb05400.x

75. Addicott MA, Yang LL, Peiffer AM, Laurienti PJ. Methodological considerations for the quantification of self-reported caffeine use. Psychopharmacology. (2009) 203:571-8. doi: 10.1007/s00213-008-1403-5

Conflict of Interest: The authors declare that the research was conducted in the absence of any commercial or financial relationships that could be construed as a potential conflict of interest.

Publisher's Note: All claims expressed in this article are solely those of the authors and do not necessarily represent those of their affiliated organizations, or those of the publisher, the editors and the reviewers. Any product that may be evaluated in this article, or claim that may be made by its manufacturer, is not guaranteed or endorsed by the publisher.

Copyright $\odot 2022$ Lin, Weibel, Landolt, Santini, Garbazza, Kistler, Rehm, Rentsch, Borgwardt, Cajochen and Reichert. This is an open-access article distributed under the terms of the Creative Commons Attribution License (CC BY). The use, distribution or reproduction in other forums is permitted, provided the original author(s) and the copyright owner(s) are credited and that the original publication in this journal is cited, in accordance with accepted academic practice. No use, distribution or reproduction is permitted which does not comply with these terms. 